\title{
Dendritic Molecular Assemblies for Singlet Oxygen Generation: meso-Tetraphenylporphyrin-Based Biphotonic Sensitizers with Remarkable Luminescence
}

\author{
Dandan Yao, , ${ }^{\mathrm{a}, \mathrm{b}}$ Vincent Hugues, ${ }^{\mathrm{c}}$ Mireille Blanchard-Desce, ${ }^{\mathrm{c}}$ Olivier Mongin, ${ }^{\mathrm{a}}$ Christine $\mathbf{O}$. \\ Paul-Roth, ${ }^{*, a, b}$ Frédéric Paul ${ }^{*, a}$ \\ a. Institut des Sciences Chimiques de Rennes (UMR CNRS 6226) Université de Rennes 1, Campus de Beaulieu, \\ 35042 Rennes Cedex (France), E-mail: frederic.paul@univ-rennes1.fr. \\ b. Institut National des Sciences Appliquées, INSA-ISCR, 35043 Rennes Cedex, France \\ E-mail: christine.paul@insa-rennes1.fr \\ c. Institut des Sciences Moléculaires (UMR CNRS 5255), Université de Bordeaux, 351 cours de la Libération, \\ 33405 Talence, France, E-mail: m.blanchard-desce@ism.u-bordeaux1.fr.
}

Electronic Supplementary Information (ESI) available: Synthesis, NMR characterization and TPA spectra of 1-4.

Four new TPP-based chromophores (1-4) peripherally functionalized with dendrons containing 2-fluorenyl groups were studied for their potential to serve in photodynamic therapy. Their linear and nonlinear optical properties were derived. With significant TPA cross-sections at $790 \mathrm{~nm}$, good singlet oxygen generation capabilities and relatively large intrinsic fluorescence, sensitizers such as 1 , might become particularly appealing for theranostics.

Due to their large occurrence in nature and biological importance for life, porphyrins have attracted considerable attention as chromophores for various uses connected with living organisms. ${ }^{1}$ In particular, their capability to generate singlet oxygen $\left({ }^{1} \mathrm{O}_{2}\right)$ upon photoexcitation has been abundantly studied for applications in photodynamic therapy (PDT), ${ }^{2-4}$ leading for instance to the clinical use of selected porphyrin derivatives such as photofrin ${ }^{\circledR}$ or visudyne ${ }^{\circledR} .5,6$ More recently, advances in this field focused in the development of chromophores possessing larger two-photon absorption (TPA) cross-sections and likely to be excited with NIR lasers, thereby allowing for enhanced penetrability in tissues of the exciting beam, better spatial control of the ${ }^{1} \mathrm{O}_{2}$ generation and overall lower photodamages to organisms compared to visible excitation. ${ }^{5-9, ~ \# ~ I n ~ t h i s ~ c o n n e c t i o n, ~ p o r p h y r i n ~ a r r a y s ~ w i t h ~}$ TPA cross-sections and impressive photosensitizing activities have been reported. ${ }^{14-17}$ However, for these compounds the TPA enhancement mostly results from quasi-resonance of the exciting beam with the one-photon absorbing (OPA) $Q$ state at low energy. ${ }^{17-19}$ In order to obtain photosensitizers without any interfering OPA state, ${ }^{\ddagger}$ another strategy was also explored. It consisted in functionalizing the porphyrin core with good two-photon absorbers at the periphery. ${ }^{20}$ For such derivatives, the porphyrin-centered excited state active for oxygen photo-sensitizing can then be populated by resonant energy transfer (FRET) following biphotonic excitation of the TPA chromophores. Molecular assemblies with 
dendritic, ${ }^{21-26}$ dyadic $^{27-29}$ or even more complex architectures ${ }^{30-33}$ were successfully tested in this context.

An even more recent concern in this field is to simultaneously perform imaging and curing of living tissues in a dual therapic and diagnostic (also called "theranostic") approach. ${ }^{20,34,35}$ This turned out to be a quite challenging task to achieve with porphyrin-based photosensitizers, since the lowest $(Q)$ excited states of porphyrin (which actually sensitizes oxygen) exhibit often only a modest to negligible fluorescence. ${ }^{36}$ Apart from few porphyrin arrays, ${ }^{14}$ most of the porphyrin-based sensitizers obtained so far are poorer luminophores than $\mathbf{H}_{\mathbf{2}}$ TPP and are therefore only of modest interest for imaging purposes. ${ }^{37}$ Thus, the development of analogues of these compounds exhibiting enhanced luminescence remains an appealing and challenging task. ${ }^{20,38}$

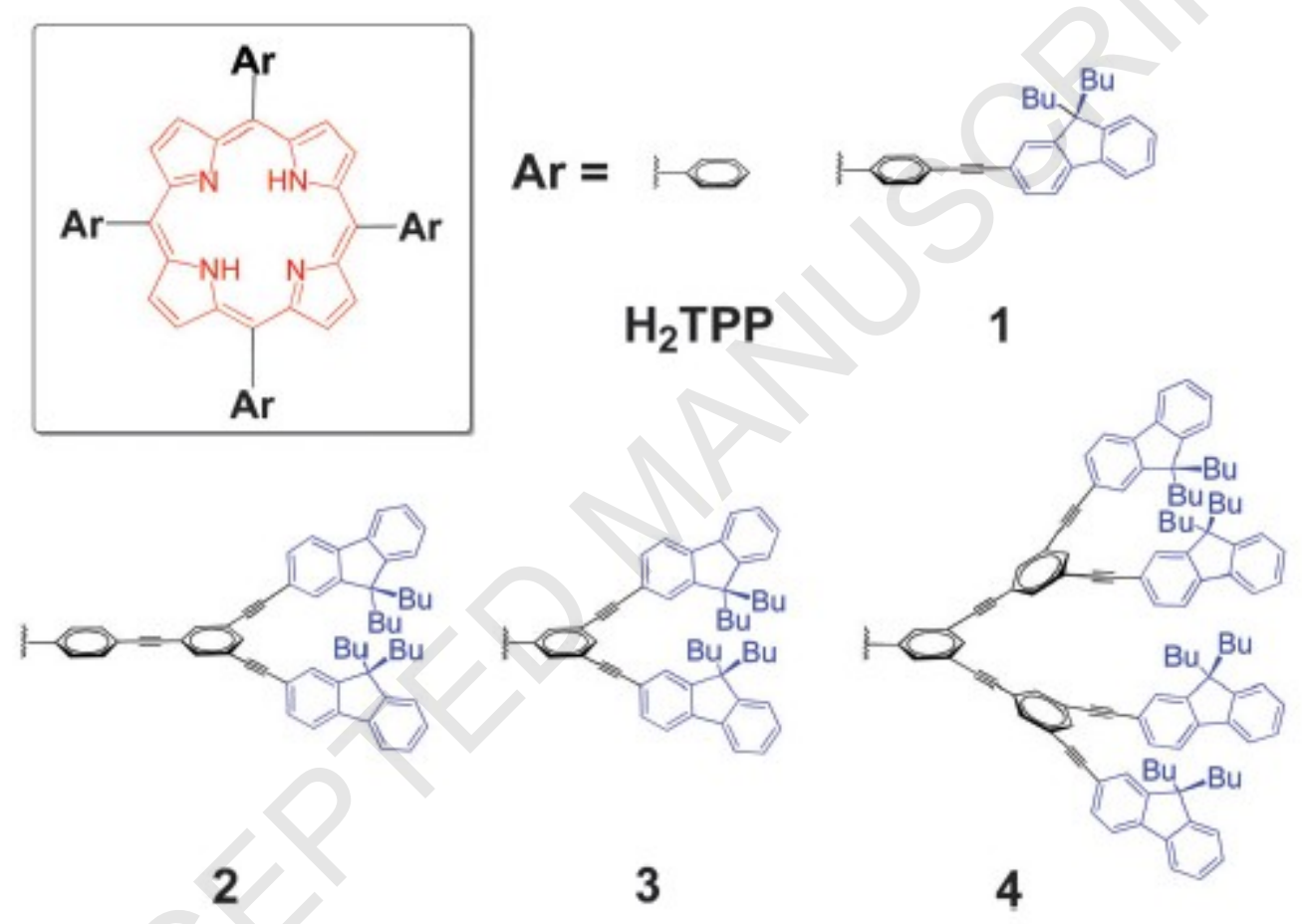

Scheme 1. Selected $\mathrm{H}_{2}$ TPP-based Photosensitizers.

In this respect, we wondered about the performances of peripherally functionalized meso-tetraphenylporphyrins ( $\mathbf{H}_{\mathbf{2}}$ TPP) derivatives such as $\mathbf{1 - 4}$. Fluorene is indeed a powerful fluorophore, ${ }^{39}$ giving rise to compounds with fairly high TPA cross-sections, especially when extended conjugation is present. ${ }^{40}$ Accordingly, we could previously show that related dendritic structures present a significantly improved fluorescence compared to that of $\mathbf{H}_{2}$ TPP, due to an efficient energy transfer taking place from the peripheral fluorene units to the central TPP core. ${ }^{36,41,42}$ In comparison, preservation of some ${ }^{\S} \pi$-overlap between the peripheral fluorenyl units and the central TPP core in 1-4 might even be more beneficial to both TPA and luminescence. ${ }^{43,44}$ Furthermore, given that TPP derivatives are often able to efficiently generate ${ }^{1} \mathrm{O}_{2}$ upon excitation, we also wondered about the potential of such 
structures for photodynamic therapy. In line with our expectations, we now show that these new TPP-based dendritic derivatives constitute quite promising structures for such uses.

The new compounds 1-4 were obtained in $28-13 \%$ yield in one step from the corresponding functional aldehydes and pyrrole in propionic acid under typical Adler-Longo conditions. ${ }^{45}$ The functional aldehydes where themselves obtained from the brominated aldehydes and aryl the ad hoc arylethynyl precursors following a classic multistep synthetic approach based on Sonogashira couplings. The resulting porphyrins were completely characterized by elemental analysis, HRMS, ${ }^{1} \mathrm{H}$ and ${ }^{13} \mathrm{C}$ NMR (see ESI).

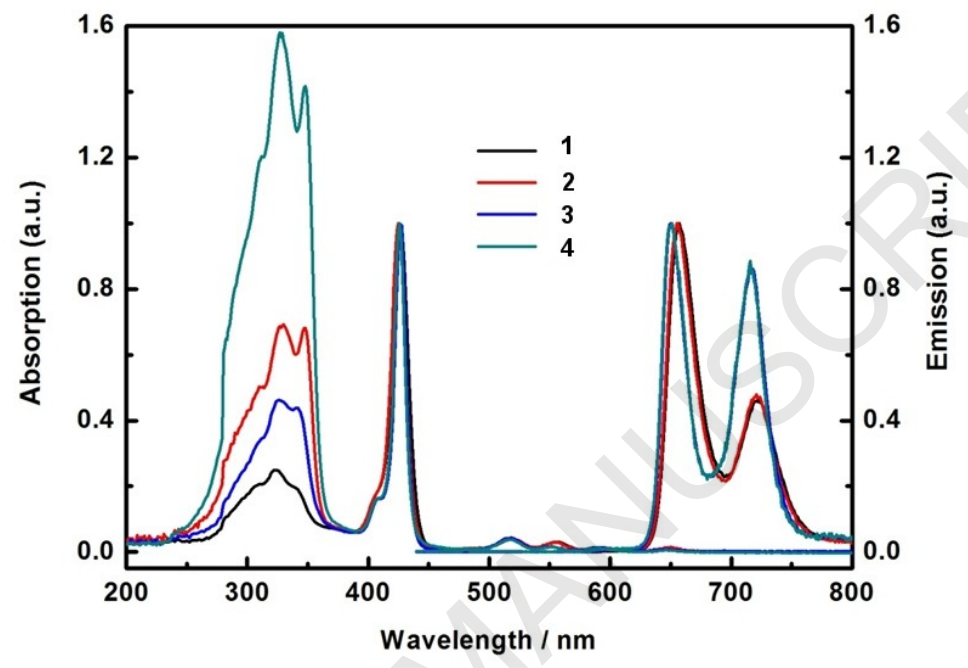

Figure 1. Absorption and Normalized Emission Spectra of 1-4 in $\mathrm{CH}_{2} \mathrm{Cl}_{2}$.

Their linear optical properties were subsequently studied. In line with data previously gathered on related structures, ${ }^{36,41,42}$ 1-4 display the typical features of the porphyrin core such as an intense Soret band near $426 \mathrm{~nm}$ and four weaker Q-bands in the 517-650 nm range along with a strong structured band near $320 \mathrm{~nm}$ corresponding to the fluorene-based $\pi^{*} \leftarrow \pi$ transition. As expected, the intensity of the latter increases when progressing from 1 to 4 (i.e. with the number of fluorenyl groups in the compound) to eventually become the most intense UV-vis absorption in $\mathbf{4}$ (Figure 1). When excited at this particular wavelength $(320 \mathrm{~nm})$, all these molecules fluoresce in the red, corresponding to an emission from the Qstates which are the lowest singlet excited states, with essentially no fluorescence stemming from the fluorenyl-based $\pi^{*} \leftarrow \pi$ state. Comparison between the absorption spectra and normalized excitation spectra allows pointing out a very efficient energy transfer to the lowest singlet energy state (above $90 \%$ efficiency) for all compounds. Also, the fluorescence quantum yields were derived for 1-4 and were shown to be larger or comparable than for $\mathbf{H}_{\mathbf{2}}$ TPP (Table 1) or related TPP-based fluorophores. ${ }^{39}$ In this respect, two fluorenyl units at the meta-positions appear to be less effective than one fluorene unit in para-position on the meso phenyl groups of the central TPP core (compare $\Phi_{\mathrm{F}}$ for $\mathbf{1}$ and $\mathbf{3}$ ). This suggests that 1,4conjugation is an important parameter for enhancing luminescence. Otherwise a reverse 
trend than observed between $\mathbf{1}$ and $\mathbf{3}$ should have been stated based on the absorption spectra of these compounds.

TPA cross-sections were then measured for 1-4 by two-photon excitation fluorescence (TPEF). In line with our expectations, the presence of fluorenyl groups leads to a much larger effective TPA at $790 \mathrm{~nm}$ than for $\mathbf{H}_{\mathbf{2}}$ TPP. The later shows as strict quadratic dependence on the power of the incoming laser beam, in line with an instant biphotonic excitation (see ESI), and opens thereby access to minute spatial control of this phenomenon with 1-4 for any applied use. Again, comparison between 1 and $\mathbf{3}$ reveals that one 2-alkynylfluorenyl group in para positions to each peripheral meso-phenylene groups of the TPP core is much better for TPA than two such groups in meta-positions, further outlining the importance of crossconjugation through the meso-phenylene groups. Albeit $\pi$-conjugation between the dendrons and the porphyrin core must be somewhat limited in the most stable (non planar) conformers, ${ }^{\S}$ this observation nevertheless emphasizes the importance of that particular feature for TPA. Albeit much lower than for 1-4, the fluorescence of many commercial porphyrin-based photosensitisers is often used for one-photon imaging during clinical trials. $^{37}$

\begin{tabular}{|c|c|c|c|c|c|c|c|c|c|c|c|c|}
\hline Cpnd & $\begin{array}{l}\text { fluorenes/ } \\
\text { porphyrin }\end{array}$ & $\begin{array}{l}\lambda_{\text {abs }}^{\max } \\
(\mathrm{nm}) \\
\text { UV band }\end{array}$ & $\begin{array}{l}\lambda_{\mathrm{abs}}^{\max } \\
(\mathrm{nm}) \\
\text { Soret }\end{array}$ & $\begin{array}{l}\lambda_{\alpha \mathrm{bs}}^{\max } \\
(\mathrm{nm}) \\
\text { Q-bands }\end{array}$ & & $\begin{array}{l}\lambda_{\mathrm{em}} \\
(\mathrm{nm})\end{array}$ & $\Phi_{\mathrm{F}}^{a}$ & $\Phi_{\Delta}^{b}$ & $1-\Phi_{\mathrm{F}}-\Phi_{\Delta}^{c}$ & $\begin{array}{l}\lambda_{2 \mathrm{PA}}^{\max } \\
(\mathrm{nm})\end{array}$ & $\begin{array}{l}\sigma_{2}^{\max } \\
(\mathrm{GM})^{d}\end{array}$ & $\begin{array}{l}\text { Enhanc } \\
\text { ement } \\
\text { factor }^{e}\end{array}$ \\
\hline $\mathrm{H}_{2} \mathrm{TPP}$ & 0 & / & 417 & $\begin{array}{l}514, \quad 549, \\
647\end{array}$ & 590 & 650,716 & 0.11 & 0.60 & 0.29 & 790 & $12^{f}$ & 1 \\
\hline 1 & 4 & 324 & 427 & $\begin{array}{l}518, \quad 555, \\
650\end{array}$ & 592 & 657,722 & 0.20 & 0.70 & 0.10 & 790 & 380 & 37 \\
\hline 2 & 8 & 330 & 425 & $\begin{array}{l}520, \quad 555 \\
650\end{array}$ & 592 & 655,721 & 0.19 & 0.65 & 0.16 & 790 & 190 & 17 \\
\hline 3 & 8 & 326 & 427 & $\begin{array}{l}517, \quad 552, \\
646\end{array}$ & 589 & 650,718 & 0.11 & 0.59 & 0.30 & 790 & 200 & 16 \\
\hline 4 & 16 & 327 & 426 & $\begin{array}{l}517, \quad 552, \\
646\end{array}$ & 590 & 651,716 & 0.13 & 0.56 & 0.31 & 790 & 290 & 23 \\
\hline
\end{tabular}

\footnotetext{
${ }^{a}$ Fluorescence quantum yield determined relative to $\mathrm{H}_{2}$ TPP in toluene, upon excitation at the Soret band. ${ }^{b}{ }^{1} \mathrm{O}_{2}$ formation quantum yield determined relative to $\mathrm{H}_{2}$ TPP in $\mathrm{CH}_{2} \mathrm{Cl}_{2}\left(\Phi_{\Delta}[\mathrm{TPP}]=0.60\right)$ upon excitation in the Soret band of the compounds (425 nm). ${ }^{c}$ Upper bound yield of non radiative decay processes other than intersystem crossing. ${ }^{d}$ Intrinsic TPA cross-sections measured by TPEF in the fs regime; a fully quadratic dependence of the fluorescence intensity on the excitation power is observed and TPA responses are fully non-resonant. ${ }^{e}$ $\Phi_{\Delta} . \sigma_{2}{ }^{\max }$ factor relative to that for $\mathbf{H}_{\mathbf{2}}$ TPP. ${ }^{f}$ Data from lit. ${ }^{47}$
}

While two-photon excitation has been demonstrated for many of them, ${ }^{5,} 6$ the corresponding cross-sections compare usually to that of $\mathbf{H}_{\mathbf{2}}$ TPP (i.e. are typically at least one order of magnitude below these found for 1-4). In this respect, the presence of large TPA cross-sections allied to relatively large fluorescence quantum yields in 1-4 constitutes presently a quite appealing property for imaging purposes.

Finally, the quantum yields for singlet oxygen generation were determined for 1-4 (ESI). Quite interestingly, we found that these are better or compare to that of $\mathbf{H}_{\mathbf{2}} \mathbf{T P P}$, revealing 
that fluorescence is not obtained at the expense of singlet oxygen generation for these compounds. For 1 , this leads to a remarkable 37-fold enhancement of the $\Phi_{\Delta} \cdot \sigma_{2}{ }^{\max }$ factor taken as a figure of merit for two-photon singlet oxygen generation over TPP, while 16- to 23-fold enhancements were obtained for 2-4 (Table 1), outlining the interest of these compounds as biphotonic sensitizers for photodynamic therapy. These enhancements evidence the beneficial role of the peripheral fluorene-containing dendrons partly $\pi$ conjugated with the central TPP core for biphotonic photosensitization of oxygen. Note that for 1-4, taking $\Phi_{\Delta}$ as a lower bound for the yield of intersystem crossing, the sum $\Phi_{\mathrm{F}}+\Phi_{\Delta}$ is close to unity. With this kind of structure, this leaves little room for further improvement of either fluorescence or singlet oxygen generation subsequent to monophotonic excitation. This also means that for these luminophores, non radiative processes such as internal conversion contribute less than fluorescence for regenerating the ground state.

In conlusion, we have reported here the photochemical study of four new TPPbased dendritic chromophores (1-4) possessing 4 to 16 ethynylfluorenyl groups at their periphery. In comparison to $\mathbf{H}_{\mathbf{2}} \mathbf{T P P}$, we show that these derivatives possess a much improved ${ }^{1} \mathrm{O}_{2}$ generation capability upon biphotonic excitation and also overall better fluorescence yields. Furthermore, a strict quadratic dependence of the twophoton excited fluorescence (TPEF) intensity on the fluence of the exciting laser beam was established in all cases, allowing optimal spatial resolution to be expected from these chromophores for imaging and therapy. Thus, 1, 2 and $\mathbf{4}$ present TPA crosssections at $790 \mathrm{~nm}$ and also a specific red fluorescence which supersede those of many TPP-based photosensitizers developed so far for two-photon photodynamic therapy. These performances can be traced back to their unique structures in which the peripheral fluorenyl preserve some $\pi$-overlap with the central TPP core at the meso positions, allowing some of them to remain partly conjugated, without strongly red shifting the lowest porphyrin-based transitions. These peculiar structural features essentially preserve the linear optic signature of the TPP core in absorption and emission and thus afford an optimal transparency window, while inducing an overall faster radiative decay and boosting the TPA cross-section around $800 \mathrm{~nm}$. In conclusion, this work emphasizes the remarkable photochemical properties of molecular assemblies incorporating TPP and 2-fluorenyl moieties in "semidisconnected ${ }^{\prime 20}$ conjugates well known their robustness and photostablity. ${ }^{\S}$ In regard to the simplicity and synthetic versatility of their structure, when suitably solubilized in physiological media by proper functionalization, ${ }^{26}$ compounds such as $\mathbf{1}$, likewise to recently reported chlorines, ${ }^{52}$ might become quite promising photosensitizers for theranostics. Work along these lines and also devoted to study the energy transfer process in these remarkable compounds is underways. 


\section{Experimental}

General procedure for synthesis of 1-4. A mixture of the corresponding aldehyde $(1.72 \mathrm{mmol})$ and propionic acid $(6.5 \mathrm{~mL})$ was heated to $120{ }^{\circ} \mathrm{C}$. After dropwise addition of a solution of pyrrole (1 eq) in propionic acid $(1.0 \mathrm{~mL})$, the reaction medium was further kept refluxing for 1.5-5.5 h (see ESI). After cooling at room temperature, $\mathrm{MeOH}$ was added to the reaction mixture and the precipitate was filtered. The residue could be purified by repeated chromatography on silica using petroleum ether $/ \mathrm{CH}_{2} \mathrm{Cl}_{2}$ mixtures as eluant. The title compounds were isolated in $28 \%-13 \%$ yield.

\section{Acknowledgments}

DY thanks the China Scholarship Council for a PhD grant. The CNRS is acknowledged for financial support.

\section{Notes}

\# For recent examples of TPA-PDT, see for instance refs 10-13.

¥ The interference between OPA and TPA, can limitate achievement of an optimal 3D-spatial resolution in some cases. Indeed, it has been shown with some of these compounds that the generation of the excited state on the laser fluence is not always strictly quadratic at ambient temperatures in certain cases. ${ }^{16,18}$

$\S$ In $\mathbf{H}_{\mathbf{2}}$ TPP, the dihedral angle between the phenyl rings and the macrocycle is not $90^{\circ}$ but closer to $60^{\circ}$, so $\pi$-conjugation is not fully disrupted. ${ }^{46}$

$\S \S$ In this connection, they were often used as active molecular components for optical limitation puposes. $^{48-51}$

\section{References}

1. K. Szaciłowski, W. Macyk, A. Drzewiecka-Matuszek, M. Brindell and G. Stochel, Chem. Rev., 2005, 105, 2647-2694.

2. J. F. Lovell, T. W. B. Liu, J. Chen and G. Zheng, Chemical Reviews, 2010, 110, 28392857.

3. L. G. Arnaut, Adv. Inorg. Chem., 2011, 63, 187-233.

4. A. Srivatsan, J. R. Missert, S. K. Upadhyay and R. K. Pandey, J. Porphyrins Phthalocyanines., 2015, 19, 109-134.

5. A. Karotki, M. Khurana, J. R. Lepock and B. C. Wilson, Photochem. Photobiol., 2006, 82, 443-452.

6. M. Khurana, H. A. Collins, A. Karotki, H. L. Anderson, D. T. Cramb and B. C. Wilson, Photochem. Photobiol., 2007, 83, 1441-1448.

7. J. D. Bhawalkar, N. D. Kumar, C. F. Zhao and P. N. Prasad, J. Clin. Laser Med. Surg., 1997, 15, 201-204.

8. G. S. He, L.-S. Tan, Q. Zheng and P. N. Prasad, Chem. Rev., 2008, 108, 1245-1330. 
9. M. Pawlicki, H. A. Collins, R. G. Denning and H. L. Anderson, Angew. Chem. Int. Ed., 2009, 48, 3244-3266.

10. M. Gary-Bobo, Y. Mir, C. Rouxel, D. Brevet, I. Basile, M. Maynadier, O. Vaillant, O. Mongin, M. Blanchard-Desce, A. Morere, M. Garcia, J.-O. Durand and L. Raehm, Angew. Chem., Int. Ed., 2011, 50, 11425-11429.

11. C. Monnereau, T. Gallavardin, C. Armagnat, P.-H. Lanoe, O. Maury, S. Marotte, Y. Leverrier, P. L. Baldeck and C. Andraud, Proc. SPIE, 2011, 8103, 81030N/81031$81030 \mathrm{~N} / 81039$.

12. J. Qian, D. Wang, F. Cai, Q. Zhan, Y. Wang and S. He, Biomaterials, 2012, 33, 48514860.

13. J. R. Starkey, E. M. Pascucci, M. A. Drobizhev, A. Elliott and A. K. Rebane, Biochim. Biophys. Acta, 2013, 1830, 4594-4603.

14. M. Drobizhev, Y. Stepanenko, Y. Dzenis, A. Karotki, A. Rebane, P. N. Taylor and H. L. Anderson, J. Am. Chem. Soc., 2004, 126, 15352-15353.

15. K. Ogawa, H. Hasegawa, Y. Inaba, Y. Kobuke, H. Inouye, Y. Kanemitsu, E. Kohno, T. Hirano, S.-I. Ogura and I. Okura, J. Med. Chem., 2006, 49, 2276-2283.

16. S. Achelle, P. Couleaud, P. Baldeck, M.-P. Teulade-Fichou and P. Maillard, Eur. J. Org. Chem. , 2011, 1271-1279.

17. D. Y. Kim, T. K. Ahn, J. H. Kwon, D. Kim, T. Ikeue, N. Aratani, A. Osuka, M. Shigeiwa and S. Maeda, J. Phys. Chem. A 2005, 109, 2996-2999.

18. A. Karotki, M. Drobizhev, Y. Dzenis, P. N. Taylor, H. L. Anderson and A. Rebane, Phys. Chem. Chem. Phys., 2004, 6, 7-10.

19. M. Drobizhev, Y. Stepanenko, Y. Dzenis, A. Karotki, A. Rebane, P. N. Taylor and H. L. Anderson, J. Phys. Chem. B, 2005, 109, 7223-7236.

20. O. Mongin, M. Sankar, M. Charlot, Y. Mir and M. Blanchard-Desce, Tetrahedron Lett., 2013, 54, 6474-6478.

21. W. R. Dichtel, J. M. Serin, C. Edder, J. M. J. Fréchet, M. Matuszewski, L.-S. Tan, T. Y. Ohulchanskyy and P. N. Prasad, J. Am. Chem. Soc., 2004, 126, 5380-5381.

22. M. A. Oar, J. M. Serin, W. R. Dichtel, J. M. J. Frechet, T. Y. Ohulchanskyy and P. N. Prasad, Chem. Mater., 2005, 17, 2267-2275.

23. M. A. Oar, W. R. Dichtel, J. M. Serin, J. M. J. Frechet, J. E. Roger, J.E. Slagla, P. A. Fleiz, L. S. Tan, T. Y. Ohulchanskyy and P. N. Prasad, Chem. Mater., 2006, 18, 3682-3692.

24. D.-I. Lee and T. Goodson, J. Phys. Chem. B, 2006, 110, 25582-25585.

25. W.-D. Jang and W.-G. Koh, Nanobiomaterials, 2014, 81-108.

26. F. Figueira, P. M. R. Pereira, S. Silva, J. A. S. Cavaleiro and J. P. C. Tomé, Current Org. Synth., 2014, 11, 110-126.

27. J.-X. Zhang, J.-W. Zhou, C.-F. Chan, T. C.-K. Lau, D. W. J. Kwong, H.-L. Tam, N.-K. Mak, K.-L. Wong and W.-K. Wong, Bioconjugate Chem., 2012, 23, 1623-1638.

28. J. X. Zhang, K.-L. Wong, W.-K. Wong, N.-K. Mak, D. W. J. Kwong and H.-L. Tam, Org. Biomol. Chem., 2011, 9, 6004-6010.

29. H. Ke, H. Wang, G. Cheng, N.-K. Mak, D. W. J. Kwong, K.-L. Wong and H.-L. Tam, Chem. Commun., 2010, 46, 6678-6680.

30. C.-Y. Chen, Y. Tang, Y.-J. Cheng, A. C. Young, J.-W. Ka and A. K.-Y. Jen, J. Am. Chem. Soc., 2007, 129, 7220-7221.

31. J. R. Starkey, A. K. Rebane, M. A. Drobizhev, F. Q. Meng, F. Q. Gong, A. J. Elliott, M. K and C. W. Spangler, Clin. Cancer Res., 2008, 14, 6564-6573. 
32. P. Avci, S. S. Erdem and M. R. Hamblin, J. Biomed. Nanotechnol., 2014, 10, $1937-$ 1952.

33. L. Cheng, C. Wang, L. Feng, K. Yang and Z. Liu, Chem. Rev., 2014, 114, 10869-10939.

34. P. Prabhu and V. Patravale, J. Biomed. Nanotechnol., 2012, 8, 859-882.

35. J. Bhaumik, A. K. Mittal, A. Banerjee, Y. Chisti and U. C. Banerjee, Nano Res., 2015, 8, 1373-1394.

36. C. O. Paul-Roth, J. A. G. Williams, J. Letessier and G. Simonneaux, Tetrahedron Lett., 2007, 48, 4317-4322.

37. L. B. Josefsen and R. W. Boyle, Theranostics, 2012, 2, 916-966.

38. R. P. Brinas, T. Troxler, R. M. Hochstrasser and S. A. Vinogradov, J. Am. Chem. Soc., 2005, 127, 11851-11862.

39. O. Mongin, T. R. Krishna, M. H. V. Werts, A.-M. Caminade, J.-P. Majoral and M. Blanchard-Desce, Chem. Commun., 2006, 915-917.

40. F. Terenziani, C. Katan, E. Badaeva, S. Tretiak and M. Blanchard-Desce, Adv. Mater., 2008, 20, 4541-4678.

41. S. Drouet and C. O. Paul-Roth, Tetrahedron, 2009, 65, 10693-10700.

42. S. Drouet, C. O. Paul-Roth and G. Simonneaux, Tetrahedron, 2009, 65, 2975-2981.

43. B. Li, J. Li, Y. Fu and Z. Bo, J. Am. Chem. Soc., 2004, 126, 3430-3431.

44. B. Li, K. Xu, M. Sun, Y. Fu, G. Yu, Y. Liu and Z. Bo, Macromolecules, 2006, 39, 456-461.

45. A. D. Adler, F. R. Longo, J. D. Finarelli, J. Goldmacher, J. Assour and L. Korsakoff, J. Org. Chem., 1967, 32, 476-476.

46. S. J. Silvers and A. Tulinsky, J. Am. Chem. Soc., 1967, 89, 3331-3337.

47. N. S. Makarov, M. Drobizhev and A. Rebane, Opt. Express, 2008, 16, 4029-4047.

48. K. J. McEwan, G. Bourhill, J. M. Robertson and H. L. Anderson, J. Nonlinear Opt. Phys. \& Mat., 2000, 9, 451-468.

49. M. Calvete, G. Y. Yang and M. Hanack, Synth. Met., 2004, 141, 231-243.

50. D. Swain, A. Rana, P. K. Panda and S. V. Rao, Chem. Phys. Lett., 2014, 610-611, 310315.

51. M. G. Silly, L. Porres, O. Mongin, P. A. Chollet and M. Blanchard-Desce, Chem. Phys. Lett., 2003, 379, 74-80.

52. E. F. F. Silva, F. A. Schaberle, C. J. P. Monteiro, J. M. Dabrowski and L. G. Arnaut, Photochem. Photobiol. Sci., 2013, 12, 1187-1192. 